\title{
ASSESSMENT OF STUDENTS' COGNITIVE-AFFECTIVE STATES IN LEARNING WITHIN A COMPUTER-BASED ENVIRONMENT: EFFECTS ON PERFORMANCE
}

\author{
${ }^{1}$ Ruili Wang, ${ }^{2}$ Hokyoung Ryu \& ${ }^{3}$ Norliza Katuk \\ ${ }^{1}$ School of Engineering and Advanced Technology (SEAT), Massey \\ University Auckland, New Zealand \\ ${ }^{2}$ Department of Industrial Engineering, Hanyang University Seoul, Korea \\ ${ }^{3}$ School of Computing, Universiti Utara Malaysia
}

r.wang@massey.ac.nz; hokyoung.ryu@gmail.com; k.norliza@uum.edu.my

\begin{abstract}
Students' cognitive-affective states are human-elements that are crucial in the design of computer-based learning (CBL) systems. This paper presents an investigation of students' cognitiveaffective states (i.e., engaged concentration, anxiety, and boredom) when they learn a particular course within CBL systems. The results of past studies by other researchers suggested that certain cognitive-affective states; particularly boredom and anxiety could negatively influence learning in a computer-based environment. This paper investigates the types of cognitive-affective state that students experience when they learn through a specific instance of CBL (i.e., a content sequencing system). Further, research was carried to understand whether the cognitive-affective states would influence students' performance within the environment. A one-way between-subject-design experiment was conducted utilizing four instruments (i) CBL systems known as IT-Tutor for learning computer network, (ii) a pre-test, (iii) a post-test, and (iv) self-report inventory to capture the students' cognitive-affective states. A cluster analysis and discriminant function analysis were employed to identify and classify the students' cognitiveaffective states. Students were classified according to their prior knowledge to element the effects of it on performance. Then, non-parametric statistical tests were conducted on different pairs of cluster of the cognitive-affective states and prior knowledge to determine differences on students' performance. The results of this study suggested that all the three cognitive-affective states were experienced by the students. The cognitive-affective states were found to have positive effects on the students' performance.
\end{abstract}


This study revealed that disengaged cognitive-affective states, particularly boredom can improve learning performance for lowprior knowledge students.

Keywords: Computer-based learning, cognitive-affective states, learning engagement, learning experience.

\section{INTRODUCTION}

Picard (2003) proposed an inter-disciplinary research known as affective computing to improve computing experience of users. It is a growing area that has attracted researchers and developers from around the world. Affective computing studies and identifies emotions of individuals when they interact with computer systems. The purpose of identifying their emotions is to allow the intended applications to use the data; hence they are able to respond appropriately to these emotions. Consequently, this will provide users with an interactive and engaging computing environment.

Affective computing has also been a fundamental element in designing and developing adaptive learning systems (Kalyuga, 2011). This is due to the fact that learning process is complex (Bennet \& Bennet, 2008) and involves students' cognitive activities and emotions. Therefore, researchers suggested that effective and meaningful learning can be achieved when students have positive cognitive as well as emotional states during learning. From the perspective of computer-based learning (CBL), students' emotions will ensure the effectiveness of a learning process (Khan, Weippl, \& Tjoa, 2009). The examples of emotions in CBL are confusion, boredom, delight, surprise, frustration, and engaged (Baker, D’Mello, Rodrigo, \& Graesser, 2010).

In general, emotions in learning can be divided into positive and negative (Pekrun, Goetz, Titz, \& Perry, 2002). Engaged and enjoyment are two examples of positive emotions, while boredom and anxiety are those that have been categorized as negative emotions. Some emotions such as anxiety and boredom affect learning within a computer-based environment in negative way (Baker et al., 2010). This has been the main reason and motivation to the study reported herein. It is important to take note that CBL systems are available in different forms of mode and technology, ranging from static websites to dynamic intelligent tutoring systems. Also, the learning dimension of students covers a number of different outcome variables such as motivation, performance, learning outcomes, knowledge transfer and knowledge retention etc. It is believed that CBL's effects on learning would highly rely on various 
factors and it is quite hard to be generalized. Hence, the authors are interested to know whether students' emotions within a specific instance of CBL would affect their learning performance. Content sequencing systems were emphasized and utilized to understand how emotions affect students' learning performance within this type of CBL. The emotions are limited to three that are frequently used in other studies; a combination of both positive (i.e., engaged concentration) and negative (boredom and anxiety) emotions.

The outcomes of this study are expected to provide some inputs for instructional designers and CBL system developers on the importance of considering emotions during the process. Specific emotions that are directly related to learning process could potentially affect students' performance within this environment. Hence, appropriate design of the system is needed. In the context of the content sequencing systems, the design could be improved to allow the integration of emotional feedback, which has received less attention (Terzis, Moridis, \& Economides, 2012). Consequently, a more adaptive and sustainable CBL environment can be created.

\section{COGNITIVE-AFFECTIVE STATES IN CBL}

\section{Motivation}

In recent years, many researchers have conducted study on human affective states with the aim to provide appropriate feedback about these states (Barreto, Zhai, \& Adjouadi, 2007). The conventional way of studying affective states was carried out through employing trained observers to record affect-related gestures or conversations that students have within a learning environment (Baker et al., 2010). Instead of trained judges, researchers also used self-report to obtain information about the students' affective states (D'Mello, Craig, \& Graesser, 2009). Recent development involves the use of sensor-devices or bio-feedback devices that are attached to users for capturing their affective states by means of biological response (Zeng, Pantic, Roisman, \& Huang, 2009).

The three methods described above are commonly found in literature and widely used for capturing affect-related information. Each of them has its own advantages and drawbacks depending on the setting of study. In terms of independent learning setting, certain methods seem to be more practical than others. For example, D’Mello et al. (2009) studied how effective expert judgment against self-report when they are used to identify affective states within learning environment. They also investigated the effectiveness of 
affective judgment in both online and offline modes. One of the important findings suggested that the online was more effective than offline self-report because it records users' feeling immediately. However, the investigation suggested that the method is only sensitive to particular affective states that are boredom and frustration. In their study, they analyzed students' dialogue features and facial expression by recruiting a group of trained judges in an offline mode. Selected affective states particularly confusion and frustration were detected more reliably through trained judges than self-report. However, they reported that trained judges were unable to show the interaction between boredom and facial expressions as well as dialogue features. Finally, D'Mello et al. (2009) recommended that self-report can accurately identify boredom, while trained judges can be used to detect confusion and frustration.

Although trained judges have more advantages than self-report in terms of detecting the number of affective states, it is only practical for face-toface setting, which is not the case of a real online independent learning. It is important to keep in mind of distance learning students, who are dispersed geographically over different places and often work independently at their convenience. They are the main users of online learning systems where human observers might not be appropriate in this setting. Apart from trained judges; the technology-based method such as bio-feedback devices could be intrusive and could impede learning as those devices are fixed on students' body during learning. These may also potentially create an uncomfortable learning environment. The use of the devices is a promising technology; however, for the time being, it is still not perfect. From the perspective of study reported herein, self-report is the only method that suitable and feasible for this setting. Hence, this method has been employed in this study as described in Apparatus Section.

A large number of studies had reported the relationships between affects and learning outcomes (Linnenbrink-Garcia \& Pekrun, 2011; Shen, Wang, \& Shen, 2009; Zembylas, 2008). The results of recent studies showed that students' learning could be influenced by negative affective states especially anxiety and boredom (Forbes-Riley \& Litman, 2011; Pekrun, Goetz, Titz, \& Perry, 2010). This has been investigated from two perspectives of learning: (i) achievements in examinations (Mann \& Robinson, 2009; Pekrun et al., 2010), and (ii) behaviours during learning interactions (Baker et al., 2010; Maïano, Therme, \& Mestre, 2011). Instructional design, as well as individual motivations and efforts are the factors that can influence learning (Johnson, Hornik, \& Salas, 2008). There are many issues pertaining to the impact of affective states within computer-based learning environment and more studies are required to fill the gap. The influence of affective states on the online 
learning process has not been fully studied, and is an underemphasized topic (Shen et al., 2009; Zembylas, 2008). Furthermore, many current research investigated general affective states which do not necessarily related to cognitive aspects of students within a CBL environment. Hence, this study intends to bridge this gap by investigating the effects of cognitive-affective states on performance within a specific instance of computer-based learning that is content sequencing system. With this regards, a sound psychological theory was selected, underpinning specific students' cognitive-affective states used in this study.

\section{Cognitive-Affective States}

Emotions, also referred to as affective states are very important parameters for effective learning (Lehman, Matthews, D’Mello, \& Person, 2008). Educational psychologists suggested that affective states can be described as common human feelings such as anger, fear, and sadness that are present in any situation, or other specific states that are related to learning, such as anxiety and boredom (Vogel-Walcutt, Fiorella, Carper, \& Schatz, 2011). In a self-directed learning environment such as CBL, students' knowledge and goals always influence their affective states, and the other way round, which contributes to complicated interactions between cognition and affect (Baker et al., 2010). In terms of the definition, the authors agree with Baker's arguments which described this condition as cognitive-affective states. The term "cognitive-affective states" is more suitable to refer to all affective states that may occur during a learning process. Therefore the term will be used in the rest of this paper.

Researchers highlighted anxiety and boredom as two cognitive-affective states that negatively influence learning (Klein, Moon, \& Picard, 2002; Korobili, Togia, \& Malliari, 2010; Lehman et al., 2008; Maïano et al. 2011; Mann \& Robinson, 2009). Hence, these two states are used in this study. Unlike boredom and anxiety, engaged concentration has been found as a positive cognitive-affective state for learning.

Engaged concentration, boredom and anxiety have been described by Csikszentmihalyi (1975) in his flow theory as three cognitive states that happen when a person performs a particular activity. Flow theory emphasizes that engagement in a particular activity could produce these three mental states to an individual. First, an optimal engagement gives a person an intrinsic reward and enjoyment, which leads to an optimal experience known as "flow". In some studies, flow is also referred to as engaged concentration (Baker et al., 2010). 
On the other hand, non-optimal engagement could lead to either anxiety or boredom. Anxiety and boredom are two negative feelings that limit a person's potential from reaching its maximum level. Hence, the two feelings restrain person from achieving the optimal experience when he or she performs a particular activity. The flow theory's cognitive states are very relevant in describing cognitive-affective states in CBL. The theory has also been used by researchers (Raphael, Bachen, \& Hernández-Ramos, 2012; Ryu \& Parsons, 2012) to improve human computer interaction (HCI) aspects of learning within this environment.

An individual achieves flow when his or her skill and the challenge of particular activity are equivalent. On the contrary, if a person's skill is not sufficient to satisfy the challenge, he or she might experience anxiety. High level of skill and low level of challenge could cause boredom. Figure 1 shows four different points of cognitive states $\left(A_{1}, A_{2}, A_{3}\right.$, and $\left.A_{4}\right)$ that may be obtained when a person performs a particular activity in relation to different levels of skill and challenge.

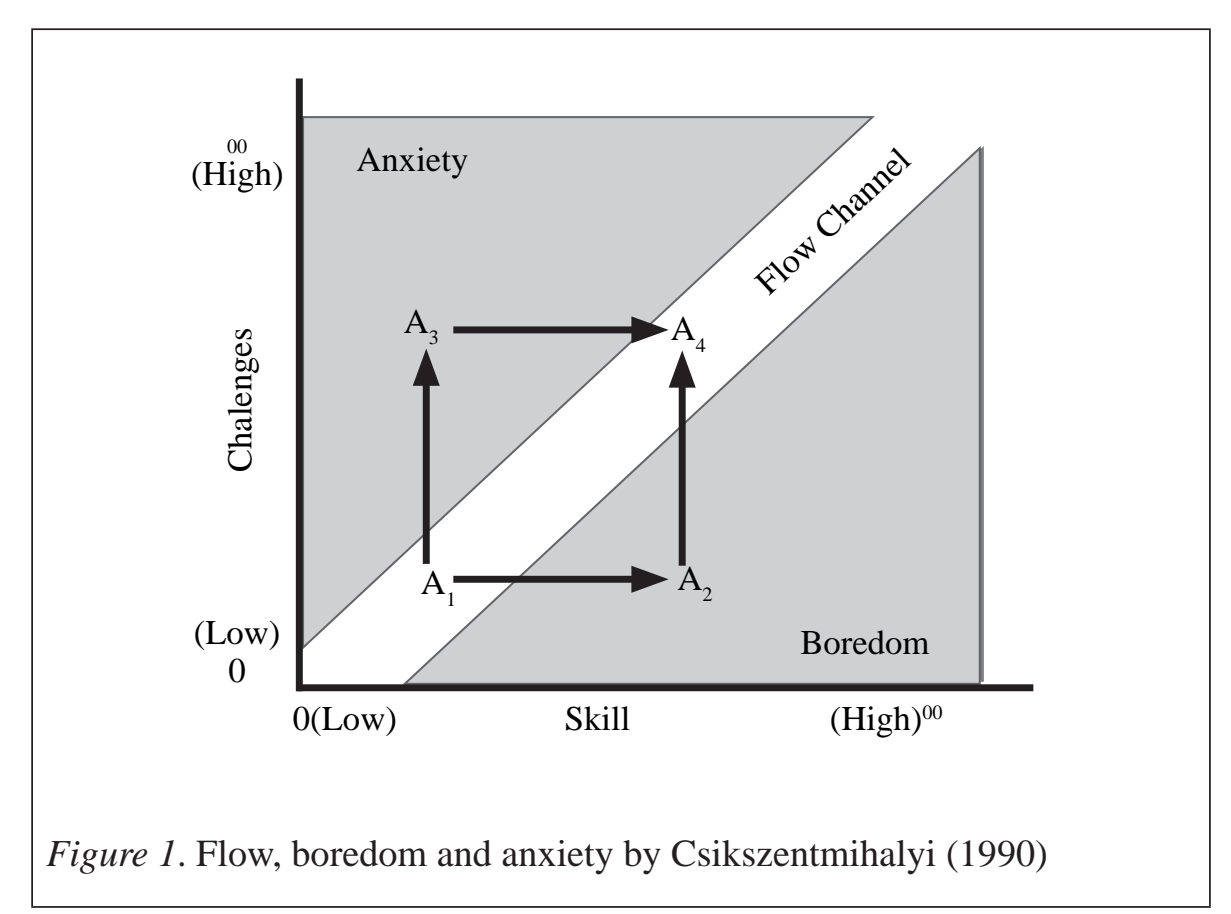

These three states were adopted in this study as the cognitive-affective states that students may experience when they learn through CBL system, particularly content sequencing system. 


\section{Content Sequencing System: An Instance of a CBL System}

Content sequencing is a specific instance of CBL systems that provides arrangement and organization of learning contents using specific algorithms or techniques to accommodate students' needs in learning. It has a direct impact especially within web-based learning where the content sequencing helps in guiding students from being "lost in the cyberspace" (Gutierrez, Pardo, \& Kloos, 2004). Organization and arrangement of leaning contents are fundamental elements for adaptive and personalized learning in CBL.

A content sequencing system (CSS) comprises of four components: user interface, student model, domain knowledge repository, and sequencing model (or engine) (Katuk, 2012) as illustrated in Figure 2. A user interface is the intermediary component between students and the CSS. The major role of a user interface is to translate an input from users into instructions that can be processed by the CSS. It is also the medium for displaying learning contents or activities to students. A student model is the component which stores information about students such as personal information (e.g., user names and passwords), learning histories and logs of usage. For each interaction that a student made with the CSS, the student model keeps a record in its database.

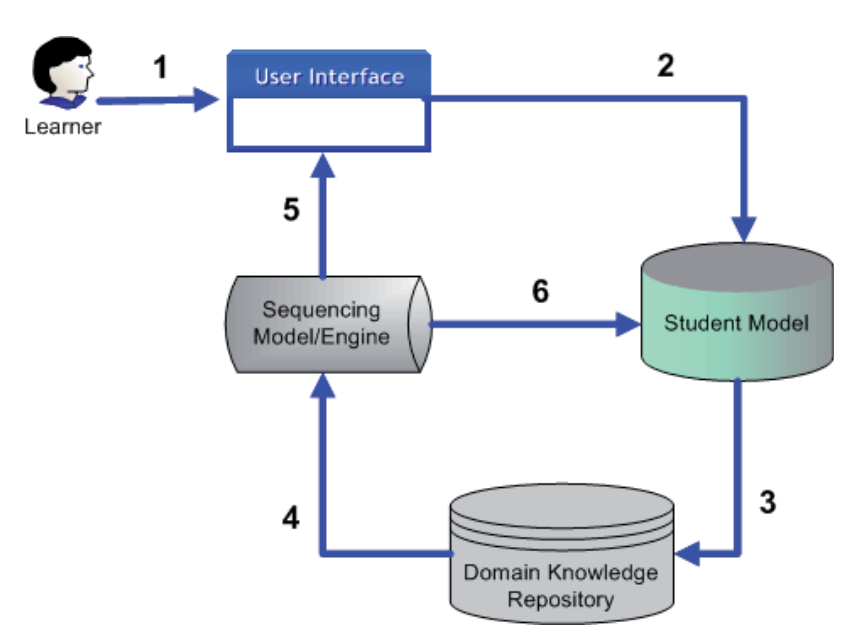

Figure 2. A generic content sequencing system architecture

In addition, a student model evaluates level of knowledge of a student and identifies the appropriate learning contents or activities. Then, the contents are obtained from a domain knowledge repository. A domain knowledge 
repository is a storage area for many types of learning materials such as explanations about theories, concepts, examples, assessment materials and others. Learning materials are organised and sequenced by a sequencing model or engine. When learning materials have been organised, they will be presented to students through the user interface. From Figure 2, the flow of process in CSS is presented below:

(i) Students communicate with CSS through the user interface component.

(ii) The user interface sends information about the students to the student model.

(iii) The student model identifies students' levels of knowledge and identifies the appropriate learning contents for them individually.

(iv) The domain knowledge repository sends the learning contents to the sequencing model or engine for further organisation.

(v) The organised contents are presented to the students through the user interface.

(vi) The sequencing model or engine sends information about the learning contents to the student model for keeping track of learning activities.

The students' learning process is illustrated in a flow chart as depicted in Figure 3. A learning session in CSS could begin with an evaluation of students' prior knowledge. Prior knowledge is usually measured through a set of quiz related to the domain of study or a simple set of questionnaire asking about the students' background of knowledge. In some CSS where prior knowledge (pre-requisite) is not required (see Gascueña and Fernández-Caballero (2005) for an example), the systems simply present a sequence of learning contents to the students. In the case where pre-requisite knowledge is required (e.g., in advanced courses), a learning session starts with an evaluation of the students' prior knowledge. Then, the students are presented with a sequence of learning contents that match their levels of knowledge. After the students undertake the learning session, their current knowledge will be evaluated through a set of quiz related to the contents that they have learned.

The students' current knowledge evaluation will determine the next step of the learning process. If students meet the learning objectives (i.e., able to answer the quiz or test which meet a certain standard), they can proceed to the next sequence of activities. If the students do not achieve a certain standard of learning outcomes, they need to undergo a reinforcement session. This learning process can be repeated for a higher level of difficulty, which involves an iteration of the same processes. 


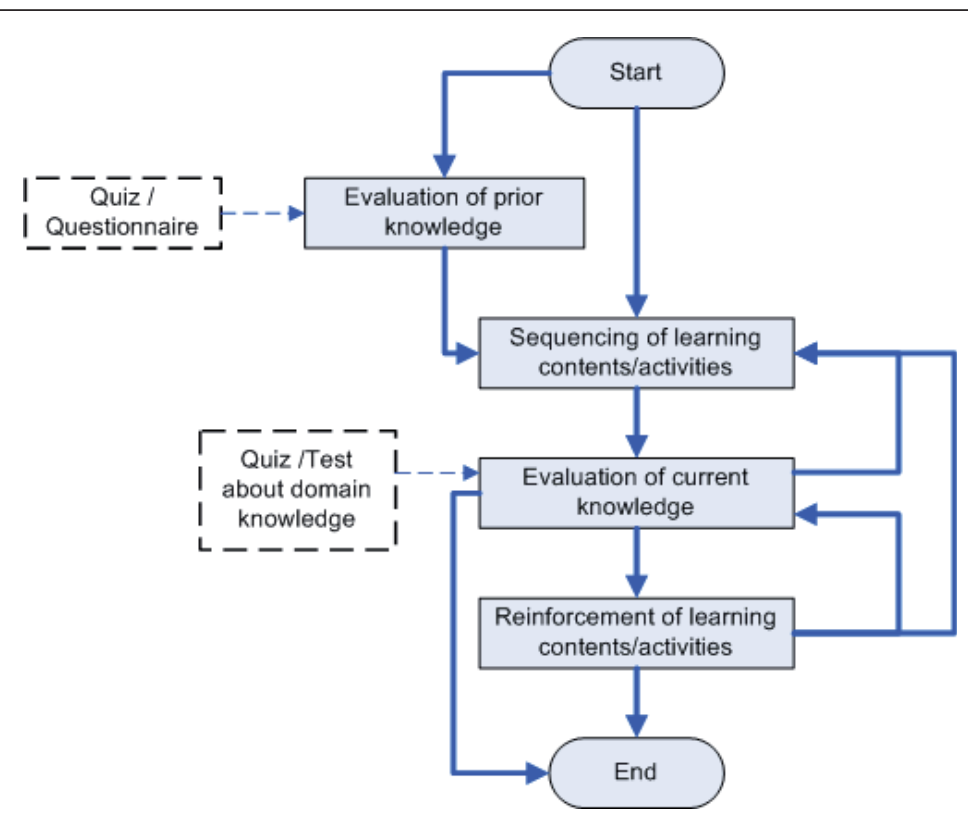

Figure 3. A generic flow of content sequencing learning process

\section{METHODOLOGY}

A field experimental study was carried out to recognize the types of the cognitive-affective states (i.e., engaged concentration, anxiety, and boredom) that students experience when they interact with a CSS; a specific instance of CBL. Furthermore, the study aimed to identify whether these cognitiveaffective states affect their performance when the students learn within this environment.

\section{Experimental Design}

An experimental study was conducted using a one-way between-subject design, where the subjects were divided into an experiment and a control group respectively. Three independent variables were identified as the following:

(i) Cognitive-affective states - three cognitive-affective states were chosen in this study; (i.e., engaged concentration, anxiety, and boredom)

(ii) Prior knowledge - students' knowledge about the domain of learning in which they obtained it from other sources. Prior knowledge is clustered in two groups, which are low and high. 
(iii) Types of CBL - comprises of two types; the content sequencing and static content.

The dependent variable was learning performance which measured students' achievement in learning from the CBL systems. Collection of data was done from the post-test scores. Three research questions (RQ) and five hypotheses were constructed for this study as below:

RQ 1 - Is there any difference in learning performance between students with difference cognitive-affective states?

RQ 2 - Is there any difference in terms of cognitive-affective states of students with different levels of prior knowledge?

RQ 3 - Is there any difference in learning performance between students who had used static content CBL and Content Sequencing CBL?

The hypotheses for the research are:

$\mathrm{HA}_{0}$ : Learning performance is similar for students with different cognitiveaffective states

$\mathrm{HA}_{1}$ : Learning performance is different for students with different cognitiveaffective states

$\mathrm{HB}_{0}$ : Cognitive-affective states are similar for students with high prior knowledge

$\mathrm{HB}_{1}$ : Cognitive-affective states are different for students with high prior knowledge

$\mathrm{HC}_{0}$ : Cognitive-affective states are similar for students with low prior knowledge

$\mathrm{HC}_{1}$ : Cognitive-affective states are different for students with low prior knowledge

$\mathrm{HD}_{0}$ : Static content and content sequencing CBL has similar effect on learning performance of high prior knowledge students

$\mathrm{HD}_{1}$ : Static content and content sequencing CBL has similar effect on learning performance of high prior knowledge students

$\mathrm{HE}_{0}$ : Static content and content sequencing CBL has similar effect on learning performance of low prior knowledge students

$\mathrm{HE}_{1}$ : Static content and content sequencing CBL has similar effect on learning performance of low prior knowledge students

\section{Subjects}

Students from a university in Malaysia and another in New Zealand were the subjects of this study. Participation was obtained from subjects who responded to author's emails and advertisements in campus notice boards. 
The study recruited 82 students that participated on a voluntarily basis (i.e., 34 and 48 from Malaysia and New Zealand respectively). From this group, 38 students (i.e., 11 males and 27 females) interacted with the content-sequencing CBL system. Further, 21 males and 23 females used the static content CBL system. An equal percentage of students were recruited from postgraduate and undergraduate levels, enrolled in various programs of study. About ten percent of the subjects were recruited from Information Technology-related programs. The rest of the respondents reported that they enrolled in various programs including Arts, Politics, and Anthropology, Human Nutrition, Accountancy, Veterinary, Animal Science, History, Volcanic Hazard, Food Technology, Education, Entrepreneurship, Business Management, Tourism, Public Management, Agribusiness Management, Marketing, and Communications. The mean age of the subjects was 28.84 years. This study was conducted in July to November 2010.

\section{Apparatus}

Two types of CBL systems, a pre- and post-test respectively, and a self-report inventory questionnaire were the apparatus used in this study. The domain knowledge for this study was "Computer Networks"; a fundamental module of Introduction to Information Technology (IT) courses. The module was used as the basis for the pre-test, post-test and the CBL systems. The content of this module covered topics of introduction to computer network, network devices and transmission media.

The pre-test consisted of ten multiple-choice questions about the module while the post-test comprised of five short-answer and long-answer questions each. The post-test was set at a higher difficulty level compared to the pre-test. Different questions were asked in both tests. The range of score for both preand post-tests is between zero and ten.

In many previous studies, it has been proven that prior knowledge affects the outcomes of computer-based learning (Jung \& Park, 2004; Kalyuga, 2005; Kopcha \& Sullivan, 2008; Mitchell, Chen, \& Mac, 2005). Based on past studies in the literature, prior knowledge can be divided into two levels, which are high and low. The prior studies found that high prior knowledge students are more likely to have higher achievement than lower prior knowledge students in the same domain of learning. In terms of learning sequence, it is suggested that prior knowledge affects one's computer-based navigation and content organisation preferences (Amadieu et al., 2009, 2010; Calisir et al., 2008; Greene et al., 2010; Jung \& Park, 2004; Kalyuga, 2005; Kopcha \& Sullivan, 2008; Mitchell, et al., 2005; Shin, et al., 1994). Those who have high 
prior knowledge prefer to create their own navigational learning paths; hence, learning activity is effective for them when they are provided with high selfcontrol over the learning content. In contrast, low prior knowledge students require high navigational support and pre-organised learning content.

The CBL systems used in this experiment shared the same user interface design as shown in Figure 4. The system was known as IT-Tutor (Katuk, 2012, 2013; Katuk, Kim, \& Ryu, 2013). The first system was a CSS, while the other one was a web-based static content e-learning system. The CSS evaluated students' individual prior knowledge, then the learning content was automatically sequenced by the system according to the evaluation of individual student's prior and current knowledge. On the other hand, the static content system did not have any sequencing mechanism where students browsed the contents in a fixed sequence. Moreover, it did not consider the student's prior and current knowledge.

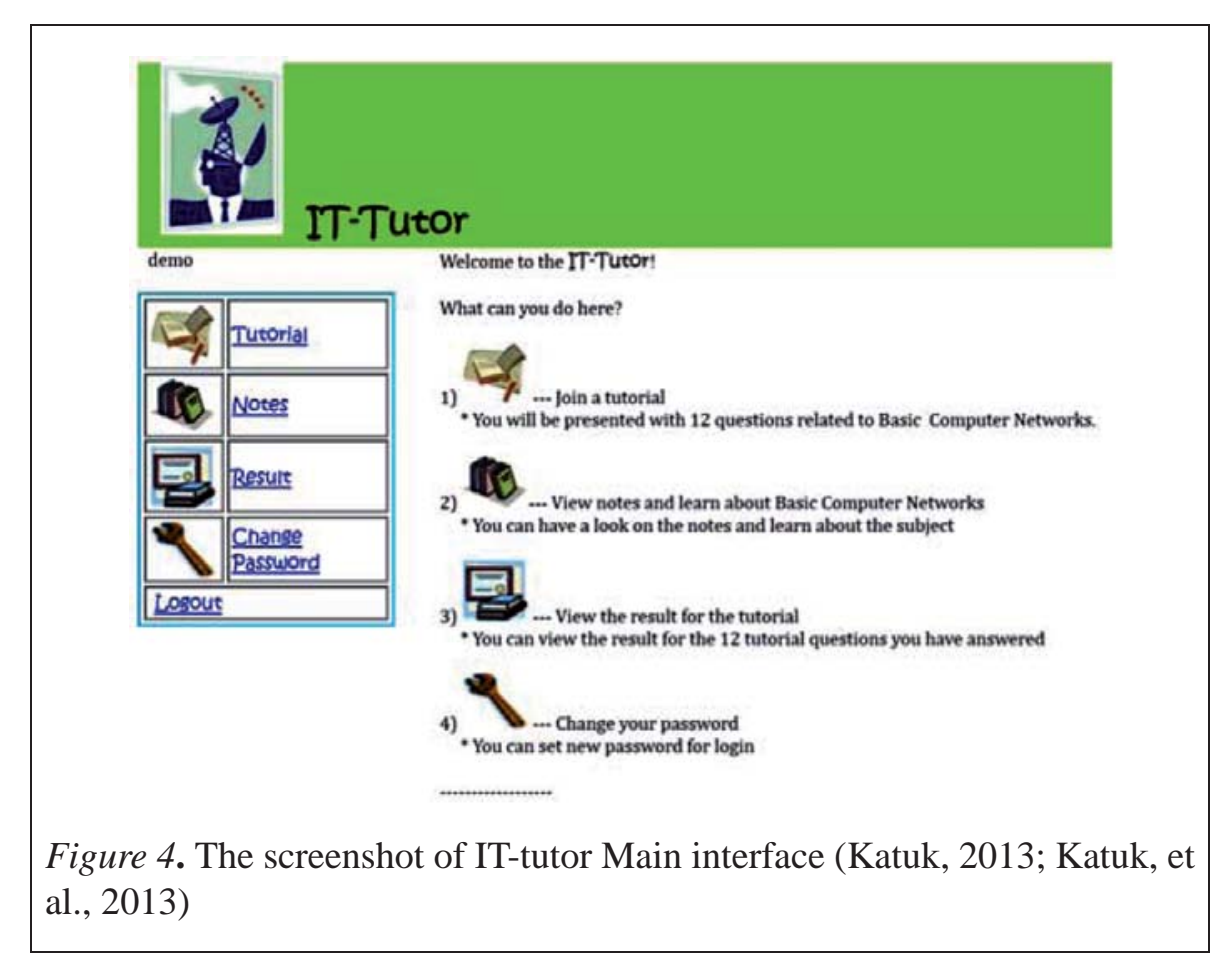

For measuring the cognitive-affective states, a self-report inventory questionnaire was used and it was adapted from Webster, Trevino, and Ryan (1993) and Park et al. (2010). Originally, it was used to measure engagement in relation to flow theory (Csikszentmihalyi, 1975). The instrument contained twelve questions and used a five-point Likert scale. 
Self-report was chosen in this research because it is the most common and an economical method for obtaining information on the respondents' cognitiveaffective states (Rogers \& Robinson, 2014; Schall, 2014). It is also more suitable for identifying specific types of emotions, especially boredom. On the other hand, many advanced technology for capturing emotion states are very expensive, greatly intrusive, and go above the skill of typical researchers (Schall, 2014). Moreover, these are not suitable for real setting of online learning as they require additional devices to be configured before interaction starts. Although self-report is retrospective and does not provide real-time assessment, it has been the major method used in psychological research for identifying emotions (Kim \& Pekrun, 2014; Ronan, Dreer, Maurelli, Ronan, \& Gerhart, 2014; Ulbricht, Berg, Fadel, \& Quevedo, 2014). It is a non-invasive method whereby respondents answered just few questions immediately after they completed interaction with the CBL system (Ulbricht et al., 2014). The self-report inventory on cognitive-affective states used in this study was independent and did not lead to social-desirability bias, guaranteeing the reliability and validity of the data (Chan, 2008).

\section{Procedure}

The experimental study was conducted online where the students were given the web address to access the materials. The students performed the tasks at their own convenience. Firstly, the students were given the information sheet and they gave their consent to participate in the study. Then, they answered the pre-test. A random binary number generator was utilized to assign the students into two groups of the CBL systems (i.e., the content sequencing and static content) after they completed the pre-test. After that, the students interacted with the CBL systems and learned the material at their own pace. All students' interactions were recorded in a database. In order to maintain the reliability and accuracy of the data, the systems were programmed to automatically log off when students became inactive ${ }^{1}$. The students answered the self-report questionnaire after they completed the CBL session. Finally, the students were required to answer the post-test.

\footnotetext{
${ }^{1}$ Interactions are identified through certain actions such as button clicking, mouse pointing, and page scrolling. Students were considered inactive when no such actions were recorded after five minutes.
} 


\section{RESULTS}

IBM SPSS statistical software was employed for the data analysis. Firstly, a normality test was conducted on the data using Kolmogorov-Smirnov (K-S). It is suggested that the data were non-normal; hence, the analysis in this paper applied non-parametric statistics. Mann-Whitney U and Kruskall-Wallis tests were chosen for the analysis of variance between subjects (Corder \& Foremen, 2009; Sheskin, 2003).

\section{Identification of Students' Cognitive-Affective States}

A univariate cluster analysis was performed to identify students' prior knowledge and cognitive-affective states. This analysis has been commonly used for classification and also found in other studies (Hair, Anderson, Tatham, \& Black, 1995; Zhang \& Zhang, 2006). Firstly, students' prior knowledge was analysed and classified into low and high using the cluster analysis tool provided by the statistical software. Students' background of knowledge is a crucial variable in learning; hence, the students must be clustered into equivalent and homogenous groups to ensure that their performance was not influenced by the existing knowledge that they had prior to the study. The similar analysis was also applied to classify students into one of the states (i.e., engaged concentration, boredom and anxiety).

A discriminant function analysis was performed to validate the clusters produced by the univariate cluster analysis (Hill \& Lewicki, 2006). In this study, instead of the observation of physical behavioural interactions of the students, their self-report were used to detect cognitive-affective states. Hence, the self-report data is classified into two categories; low and high ratings. Engaged concentration was the first cluster where it grouped together students who scored high in their self-report.

Self-report with low score may fall into one of the states; boredom or anxiety. However, the self-report was unable to differentiate between these two states. Therefore, the post-test scores were used to cluster them accurately. This is in relation to the states suggested in flow theory (Csikszentmihalyi, 1975) where low performance and low self-report scores respectively are clustered as anxious, while high performance in the post-test with low self-report scores are assigned to the other cluster (i.e., boredom). The clusters followed the fundamental assumptions of flow theory that associated boredom and anxiety with high and low performance respectively when a person performs a task (Csikszentmihalyi, 1975). 
The discriminant function analysis verified the clusters for cognitive-affective states with 96.2 percent accuracy rate. The function also re-classified the students' cognitive-affective states accordingly as rendered in Table 1 and these clusters were used for further analysis.

Table 1

The Students' Cognitive-Affective States

\begin{tabular}{lc}
\hline \multicolumn{1}{c}{ Types of Cognitive-Affective State } & Frequency \\
\hline Engaged concentration & 64 \\
Boredom & 13 \\
Anxiety & 5 \\
Total & 82 \\
\hline
\end{tabular}

About eighty percent of the students were engaged in learning within the CBL systems. The rest were considered disengaged, with boredom and anxiety faced by thirteen and five students respectively.

In order to understand whether students with different cognitive-affective states would have different performance, the analysis of data was done and the results are presented in Table 2. The post-test's means and mean ranks were calculated according to the three clusters of cognitive-affective states. Students who were in anxiety cluster had the lowest post-test scores. In contrast, students who were in boredom clusters had the highest among all of the clusters. Kruskall-Wallis ${ }^{2}$ tests were performed to confirm whether the differences in post-test mean scores were statistically significant (Kvam \& Vidakovic, 2007). The test results confirmed that the difference in the post-test scores was significant. Hence, hypothesis HA is rejected because the test result suggested students' performance was different depending on their cognitiveaffective states.

Table 2

The Post-Test Scores across Different Affective States

\begin{tabular}{|c|c|c|c|}
\hline \multirow[t]{2}{*}{ Cognitive-Affective states } & \multicolumn{2}{|c|}{ Post-test scores } & \multirow{2}{*}{$\begin{array}{l}\text { Statistics Value with } \\
\text { Kruskall-Wallis tests }\end{array}$} \\
\hline & Means & Mean Ranks & \\
\hline Engaged concentration $(n=64)$ & 3.73 & 41.50 & $H=7.16, p=0.028, p<0.05$ \\
\hline Boredom $(n=13)$ & 4.73 & 50.60 & \\
\hline Anxiety $(n=5)$ & 1.00 & 17.40 & \\
\hline
\end{tabular}

${ }^{2}$ Mann-Whitney U and Kruskall-Wallis tests were interchangeably used depending on the number of clusters involved. 
Table 3 shows the distribution of clusters crossover between prior knowledge and cognitive-affective states. It shows that novice students comprised approximately sixty percent of the total. Many students were engaged in the given computer-based learning tasks especially from the high-prior knowledge cluster. Also, none of the student from this cluster suffered from anxiety; however, five students were clustered as suffering from boredom. For the students in low-prior knowledge cluster, majority of them were classified as engaged concentration. However, five of them were clustered in anxiety while seven students were in boredom cluster.

Table 3

The Students' Prior Knowledge Across Different Clusters of CognitiveAffective State

\begin{tabular}{lcc}
\hline \multicolumn{1}{c}{ Cognitive-Affective states } & Low-prior knowledge & High-prior knowledge \\
\hline Engaged concentration & 35 & 29 \\
Boredom & 8 & 5 \\
Anxiety & 5 & 0 \\
Total & 48 & 34 \\
\hline
\end{tabular}

Table 4 shows the post-test mean scores of six different pairs of clusters; (i) engaged-high-prior knowledge, (ii) engaged-low-prior knowledge, (iii) anxiety-high-prior knowledge, (iv) anxiety-low-prior knowledge, (v) boredom-high-prior knowledge and (vi) boredom-low-prior knowledge. The Kruskall-Wallis tests suggested that boredom-low-prior-knowledge-students had significantly higher post-test score compared to other cognitive-affective states in the same cluster. The finding of this study shows that the low-prior knowledge students in boredom cluster outperformed other students with the other two states in the same category. Hence, hypothesis HB was confirmed and hypothesis HC was rejected.

The study also aimed to identify whether the types of CBL systems that were used in this study contribute to different students' performance in learning. Table 5 shows the summary of the post-test scores for different types of CBL across different clusters of prior knowledge. It is revealed that the advanced students who learned with the static content CBL outperformed its counterpart. In contrast, content sequencing CBL had led to a higher performance of low-prior-knowledge students compared to the static content CBL. The Mann-Whitney U tests validated the difference. Hence, the results lead to confirmation of hypothesis HD and rejection of hypothesis HE. 
Table 4

The Post-Test Scores Across Different Types of Prior Knowledge and Cognitive-Affective States

\begin{tabular}{|c|c|c|c|c|c|c|c|}
\hline \multirow[t]{2}{*}{$\begin{array}{c}\text { Prior } \\
\text { knowledge }\end{array}$} & \multicolumn{2}{|c|}{$\begin{array}{c}\text { Engaged } \\
\text { concentration }\end{array}$} & \multicolumn{2}{|c|}{ Boredom } & \multicolumn{2}{|c|}{ Anxiety } & \multirow{2}{*}{$\begin{array}{l}\text { Statistics Value with } \\
\text { Kruskall-Wallis } \\
\text { tests }\end{array}$} \\
\hline & Means & $\begin{array}{l}\text { Mean } \\
\text { Ranks }\end{array}$ & Mean & $\begin{array}{l}\text { Mean } \\
\text { Ranks }\end{array}$ & Means & $\begin{array}{l}\text { Mean } \\
\text { Ranks }\end{array}$ & \\
\hline $\begin{array}{l}\text { Low-prior } \\
\text { knowledge }\end{array}$ & 2.77 & 33.40 & 4.50 & 23.90 & 1.00 & 14.4 & $\begin{array}{l}H=6.18, p=0.046 \\
p<0.05\end{array}$ \\
\hline $\begin{array}{l}\text { High-prior } \\
\text { knowledge }\end{array}$ & 4.76 & 18.30 & 5.20 & 17.40 & 0.00 & - & $\mathrm{H}=0.04, \mathrm{p}=0.842$ \\
\hline
\end{tabular}

Table 5

The Post-Test Scores Across Different Clusters of Prior Knowledge and CBL

\begin{tabular}{lccccc}
\hline \multicolumn{1}{c}{ Prior knowledge } & \multicolumn{2}{c}{$\begin{array}{c}\text { Static Content } \\
\text { CBL }\end{array}$} & \multicolumn{2}{c}{$\begin{array}{c}\text { Content } \\
\text { Sequencing CBL }\end{array}$} & $\begin{array}{c}\text { Statistics Value with } \\
\text { Mann-Whitney U tests }\end{array}$ \\
\cline { 2 - 5 } & Means & $\begin{array}{c}\text { Mean } \\
\text { Ranks }\end{array}$ & Means & $\begin{array}{c}\text { Mean } \\
\text { Ranks }\end{array}$ & \\
\hline Low-prior knowledge & 2.04 & 20.20 & 3.78 & 29.10 & $\mathrm{U}=3.94, \mathrm{p}=0.024, \mathrm{p}<0.05$ \\
High-prior knowledge & 5.11 & 18.00 & 4.47 & 16.00 & $\mathrm{U}=119.5, \mathrm{p}=0.425$ \\
\hline
\end{tabular}

Based on the analysis of different pairs of clusters above, the results suggested that boredom does not necessarily cause negative effects on performance. The findings also suggested that certain cognitive-affective states, particularly boredom could somehow improve learning performance especially for lowprior knowledge students. It is also suggested that content sequencing CBL could possibly useful for low-prior knowledge students to improve their learning performance.

\section{DISCUSSION}

One objective of this study was to investigate the types of cognitive-affective state that students may experience when they learn through a specific instance of CBL (i.e., a content sequencing system). In addition, it was also intended to identify whether the cognitive-affective states would produce different effects on students' performance within the environment. Through the field 
experiment, data were collected on students' cognitive-affective states and performance when they interact with CBL systems. The univariate cluster analysis and the discriminant function analysis classified the student cognitiveaffective states and their prior knowledge into homogenous clusters.

The results of this study suggested that students experienced all the three cognitive-affective states when they interacted with the corresponding CBL systems. About seventy-five percent of the students were engaged in the learning. In terms of performance, the study found that boredom had an effect on learning performance of low-prior knowledge students in positive way. This finding is somehow contradictory to Bakers et al.'s study (2010) that found boredom could cause negative learning outcomes on students. The followings are the possible explanations to the results reported in this paper:

(i) Age can be the factor that influence the way students handle boredom in CBL. Adults and children have different approach to endure their cognitive-affective states.

(ii) The experimental setting provided the students with flexibility in terms of time, pace, and place. This setting allows the students to find suitable time at their own willing. Compared to controlled-laboratory setting, observation on students' behavioural actions could affect their emotions (D’Mello et al., 2009).

(iii) The way how cognitive-affective states data were collected (i.e., selfreport or human observer) might also contribute to different results, as this could influence privacy and comfort in learning.

There are two possible explanations why boredom could be a positive state in improving CBL learning performance. First, the state of boredom could increase curiosity (Aart et al., 2010). This is highlighted by Aart et al. (2010) when they studied a mixed-reality game that shows the connection within boredom and curiosity. They found that curiosity is increased with the presence of boredom. The state of boredom demands for stimulating activities that will challenge students' knowledge, so that they will be able to avoid the situation (Mann \& Robinson, 2009).

Finally, it is also suggested that content sequencing CBL improves low-prior knowledge students' performance. This finding could be justified by the fact that it helps students to focus on the content rather than navigation or its organization. Students can just follow the given learning contents and eliminate additional tasks that require them to navigate or search for a particular content. This particularly helps them to engage in the learning activity and avoids them from being confused with tasks organization. 


\section{CONCLUSION}

In this paper, a study was conducted for identifying students' cognitiveaffective states when they use CBL systems. It also aimed to identify whether the cognitive-affective states have different effects on learning performance. This study found that students experienced different cognitive-affective states when they learned within a CBL environment. The results of this study suggested that most of the students may be classified as engaged concentration in the given CBL tasks. However, a small number of students were classified as disengaged and fall into either anxiety or boredom states. It is also found that boredom could improve learning performance under specific conditions which relates to the students' prior knowledge. There is scope for other researchers to explore more deeply on the cognitive-affective states in CBL within higher learning students.

The results derived from this study have encouraged the authors to study cognitive-affective states through the use of modern technology. The authors are currently studying students' facial expression by recording their interaction with content-sequencing system for learning Basic Java Programming using video and web camera. Unlike bio-feedback devices (e.g., Electrocardiography, Electromyography sensors, skin conductance sensors, blood volume pulse sensors, etc.), video and web camera are less intrusive, minimizing uncomfortable and unnecessary feelings while undergoing a learning process (Kolakowska, Landowska, Szwoch, Szwoch, \& Wrobel, 2013). This method will also be paired with self-report so that the researchers are able to compare their responses with facial expression for prediction and verification of their cognitive-affective states.

In future, the authors aim to include other variables related to student individual difference such as cultural background in the similar study. It is also intended to develop sequencing techniques that can organize learning content adaptively to fit students' needs in a flexible manner. It is also suggested that computerbased applications especially for education should adopt an interaction design model that accommodates special needs of students (Husni, Jamaludin, \& Aziz, 2013). Students' individual needs are an important element to achieve adaptive learning. Hence, the outcome of this research will be used as input to design an interface model that can accommodate user with different background of knowledge. 


\section{REFERENCES}

Aart, J. V., Bartneck, C., Hu, J., Rauterberg, M., \& Salem, B. (2010). How to behave as Alice in Wonderland-about boredom and curiosity. Entertainment Computing, 1(3), 125-137.

Amadieu, F., Tricot, A., \& Mariné, C. (2009). Prior knowledge in learning from a non-linear electronic document: Disorientation and coherence of the reading sequences. Computers in Human Behavior, 25(2), 381-388.

Baker, R. S., D’Mello, S. K., Rodrigo, M. M. T., \& Graesser, A. C. (2010). Better to be frustrated than bored: The incidence, persistence, and impact of learners' cognitive-affective states during interactions with three different computer-based learning environments. International Journal of Human-Computer Studies, 68(4), 223-241.

Barreto, A., Zhai, J., \& Adjouadi, M. (2007). Non-intrusive physiological monitoring for automated stress detection in human-computer interaction. In Human-Computer Interaction (29-38). Springer Berlin Heidelberg.

Bennet, A., \& Bennet, D. (2008). E-Learning as energetic learning. VINE, 38(2), 206-220.

Calisir, F., Eryazici, M., \& Lehto, M. R. (2008). The effects of text structure and prior knowledge of the learner on computer-based learning. Computers in Human Behavior, 24(2), 439-450.

Chan, D. (2008). So why ask me? are self-report data really that bad? in C. E. Lance \& R. J. Vandenberg (Eds.), Statistical and methodological Myths and urban legends: Doctrine, verity and fable in organizational and social sciences (309). New York: Routledge.

Corder, G. W., \& Foremen, D. I. (2009). Nonparametric statistics for nonstatisticians: A step-by-step approach. New Jessey: John Wiey \& Sons.

Csikszentmihalyi, M. (1975). Beyond boredom and anxiety: Experiencing flow in work and play San Francisco: Jossey-Bass.

Csikszentmihalyi, M. (1990). Flow: The psychology of optimal experience. New York: Harper \& Row Publishers.

D’Mello, S. K., Craig, S. D., \& Graesser, A. C. (2009). Multi-method assessment of affective experience and expression during deep learning. International Journal of Learning Technology, 4(3/4), 165-187.

Forbes-Riley, K., \& Litman, D. (2011). When does disengagement correlate with learning in spoken dialog computer tutoring? Artificial Intelligence in Education. In G. Biswas, S. Bull, J. Kay \& A. Mitrovic (Eds.), 6738, 81-89: Springer Berlin: Heidelberg.

Gascueña, J. M., \& Fernández-Caballero, A. (2005). An agent-based intelligent tutoring system for enhancing e-learning/e-teaching. International Journal of Instructional Technology and Distance Learning, 2(11), 11-24. 
Greene, J. A., Costa, L.-J., Robertson, J., Pan, Y., \& Deekens, V. M. (2010). Exploring relations among college students' prior knowledge, implicit theories of intelligence, and self-regulated learning in a hypermedia environment. Computers \& Education, 55(3), 1027-1043.

Gutierrez, S., Pardo, A., \& Kloos, C. (2004). Beyond simple sequencing: Sequencing of learning activities using hierarchical graphs Proceedings of AISTED International Conference on Web-Based Education 2004, 514-519. Austria.

Hair, J. F., Anderson, R. E., Tatham, R. L., \& Black, W. C. (1995). Multivariate data analysis (4th ed.): With readings. New Jersey: Prentice-Hall, Inc.

Hill, T., \& Lewicki, P. (2006). Statistics: Methods and applications : A comprehensive reference for science, industry, and data mining. New York: StatSoft, Inc.

Husni, H., Jamaludin, Z., \& Aziz, F. A. (2013). Dyslexic children's reading application: Design for affection. Journal of Information \& Communication Technology, 12, 1-19.

Johnson, R. D., Hornik, S., \& Salas, E. (2008). An empirical examination of factors contributing to the creation of successful e-learning environments. International Journal of Human-Computer Studies, 66(5), 356-369.

Jung, J. W., \& Park, I. W. (2004). The effects of information modality and learner's prior knowledge on the achievement of the web-based learning. In L. Cantoni \& C. McLoughlin (Eds.), World Conference on Educational Multimedia, Hypermedia and Telecommunications 2004 (1823-1828). Lugano, Switzerland: AACE.

Kalyuga, S. (2005). Prior knowledge principle in multimedia learning. In R. E. Mayer (Ed.), The Cambridge handbook of multimedia learning (325357). New York: Cambridge University Press.

Kalyuga, S. (2011). Cognitive load theory: Implications for affective computing. Paper presented at the FLAIRS Conference.

Katuk, N. (2012). Learning experience in dynamic and non-dynamic curriculum sequencing systems: A thesis presented in partial fulfilment of the requirements for the degree of Doctor of Philosophy in Information Technology at Massey University.

Katuk, N. (2013). Progressive assessment of student engagement with webbased guided learning. Interactive Technology and Smart Education, 10(2), 116-129.

Katuk, N., Kim, J., \& Ryu, H. (2013). Experience beyond knowledge: Pragmatic e-learning systems design with learning experience. Computers in Human Behavior, 29(3), 747-758. 
Khan, F. A., Weippl, E. R., \& Tjoa, A. M. (2009). Integrated Approach for the detection of learning styles and affective states. In World Conference on Educational Multimedia, Hypermedia and Telecommunications 2009, (1), 753-761.

Kim, C., \& Pekrun, R. (2014). Emotions and motivation in learning and performance. Handbook of research on educational communications and technology (65-75): Springer

Klein, J., Moon, Y., \& Picard, R. W. (2002). This computer responds to user frustration: Theory, design, and results. Interacting with Computers, 14(2), 119-140.

Kolakowska, A., Landowska, A., Szwoch, M., Szwoch, W., \& Wrobel, M. R. (2013, June). Emotion recognition and its application in software engineering. In proceedings of the 6th International Conference on Human System Interaction (HSI), 2013 (532-539). IEEE.

Kopcha, T., \& Sullivan, H. (2008). Learner preferences and prior knowledge in learner-controlled computer-based instruction. Educational Technology Research and Development, 56(3), 265-286.

Korobili, S., Togia, A., \& Malliari, A. (2010). Computer anxiety and attitudes among undergraduate students in Greece. Computers in Human Behavior, 26(3), 399-405.

Kvam, P. H., \& Vidakovic, B. (2007). Nonparametric statistics with applications to science and engineering. New Jersey: John Wiley \& Sons.

Lehman, B., Matthews, M., D’Mello, S., \& Person, N. (2008). What are you feeling? Investigating student affective states during expert human tutoring sessions. In Intelligent Tutoring Systems (50-59). Springer Berlin Heidelberg.

Linnenbrink-Garcia, L., \& Pekrun, R. (2011). Students' emotions and academic engagement: Introduction to the special issue. Contemporary Educational Psychology, 36(1), 1-3.

Maïano, C., Therme, P., \& Mestre, D. (2011). Affective, anxiety and behavioral effects of an aversive stimulation during a simulated navigation task within a virtual environment: A pilot study. Computers in Human Behavior, 27(1), 169-175.

Mann, S., \& Robinson, A. (2009). Boredom in the lecture theatre: An investigation into the contributors, moderators and outcomes of boredom amongst university students. British Educational Research Journal, 35(2), 243-258.

Mitchell, T. J. F., Chen, S. Y., \& Macredie, R. D. (2005). Hypermedia learning and prior knowledge: Domain expertise vs. system expertise. Journal of Computer Assisted Learning, 21(1), 53-64. 
Park, J., Parsons, D., \& Ryu, H. (2010). To flow and not to freeze: Applying flow experience to mobile learning. IEEE Transactions on Learning Technologies, 3(1), 56-67.

Pekrun, R., Goetz, T., Titz, W., \& Perry, R. P. (2002). Academic emotions in students' self-regulated learning and achievement: A program of qualitative and quantitative research. Educational Psychologist, 37(2), 91-105.

Pekrun, R., Goetz, T., Daniels, L. M., Stupnisky, R. H., \& Perry, R. P. (2010). Boredom in achievement settings: Exploring control-value antecedents and performance outcomes of a neglected emotion. Journal of Educational Psychology, 102(3), 531-549.

Picard, R. W. (2003). Affective computing: challenges. International Journal of Human-Computer Studies, 59(1), 55-64.

Raphael, C., Bachen, C. M., \& Hernández-Ramos, P. F. (2012). Flow and cooperative learning in civic game play. New Media \& Society, 14(8), 1321-1338.

Rogers, K. B., \& Robinson, D. T. (2014). Measuring Affect and Emotions. Handbook of the Sociology of Emotions: Volume II (283-303): Springer:

Ronan, G. F., Dreer, L., Maurelli, K., Ronan, D. W., \& Gerhart, J. (2014). Measures of Anger Practitioner's Guide to Empirically Supported measures of anger, aggression, and violence (19-86). springer.

Ryu, H., \& Parsons, D. (2012). Risky business or sharing the load? Social flow in collaborative mobile learning. Computers \& Education, 58(2), 707-720.

Schall, A. (2014). New methods for measuring emotional engagement design, user experience, and usability. User experience design practice (347357): Springer.

Shen, L., Wang, M., \& Shen, R. (2009). Affective e-Learning: Using emotional data to improve learning in pervasive learning environment. Educational Technology \& Society, 12(2), 176-189.

Sheskin, D. J. (2003). Handbook of parametric and nonparametric statistical procedures. Florida: CRC Press.

Shin, E. J., Schallert, D., \& Savenye, W. C. (1994). Effects of learner control, advisement \& prior knowledge on young students' learning in a hypertext environment. Educational Technology Research and Development, 42(1), 33-46.

Terzis, V., Moridis, C. N., \& Economides, A. A. (2012). The effect of emotional feedback on behavioral intention to use computer based assessment. Computers \& Education, 59(2), 710-721.

Ulbricht, V. N. R., Berg, C. H., Fadel, L., \& Quevedo, S. R. (2014). The emotion Component on usability testing human computer interface of 
an Inclusive learning management system learning and collaboration technologies. Designing and developing novel learning experiences (334-345): Springer.

Vogel-Walcutt, J., Fiorella, L., Carper, T., \& Schatz, S. (2011). The definition, assessment, and mitigation of state boredom within educational settings: a comprehensive review. Educational Psychology Review, 24(1), 89-111.

Webster, J., Trevino, L. K., \& Ryan, L. (1993). The dimensionality and correlates of flow in human-computer interactions. Computers in Human Behavior, 9(4), 411-426.

Zembylas, M. (2008). Adult learners' emotions in online learning. Distance Education, 29(1), 71-87.

Zeng, Z., Pantic, M., Roisman, G. I., \& Huang, T. S. (2009). A survey of affect recognition methods: Audio, visual, and spontaneous expressions. IEEE Transactions on Pattern Analysis and Machine Intelligence, 31(1), 39-58.

Zhang, L., \& Zhang, B. (2006). Quotient Space Based Cluster Analysis. In T. Y. Lin, S. Ohsuga, C. J. Liau \& X. Hu (Eds.), Foundations and novel approaches in data mining (259-270). Heidelberg: Springer. 